Tropical Journal of Pharmaceutical Research February 2020; 19 (2): 427-432

ISSN: $1596-5996$ (print); 1596-9827 (electronic)

(c) Pharmacotherapy Group, Faculty of Pharmacy, University of Benin, Benin City, 300001 Nigeria.

\title{
Efficacy of Pluronic F-127 gel containing green tea catechin extract on chronic periodontitis - A clinical study
}

Raghavendra Reddy Nagate ${ }^{1}$, M Yuvaraja ${ }^{2}$, Saad M AlQahtani ${ }^{1}$, Nabeeh A.
AlQahtani $^{1}$, Shreyas Tikare ${ }^{1}$, Shankar T Gokhale ${ }^{1}$, Ravi KS $^{1}$, Mohammed Fadul
A Elagib
${ }^{1}$ Department of Periodontics and Community Dental Sciences, College of Dentistry, King Khalid University, Abha -62529 ,

Saudi Arabia, ${ }^{2}$ Department of Periodontics, Vinayaka Mission's Shankarachariyar Dental Sciences, Salem - 636308, India

*For correspondence: Email: rnagati@kku.edu.sa

Sent for review: 6 September 2019

Revised accepted: 20 January 2020

\begin{abstract}
Purpose: To evaluate the efficacy of pluronic F-127 gel containing green tea catechin extract as a local drug delivery system in the treatment of chronic periodontitis.

Methods: A total of 20 chronic periodontitis patients participated as per the set inclusion and exclusion criteria. Complete scaling and root planing (SRP) was done for all subjects and pluronic F-127 gel containing green tea catechin was applied on one site. The contralateral site received SRP alone. The plaque index (PI), gingival index (GI), and probing pocket depth (PPD) were recorded at baseline and on the 28th day.

Results: At the 28th-day follow-up, green tea catechin tooth sites showed significantly lower mean scores $(\mathrm{Gl}=0.55, p=0.30$ and $P P D=3.35 \mathrm{~mm})$ than the corresponding SRP tooth sites $(\mathrm{GI}=1.25, \mathrm{PI}$ $=1.15$, and $P P D=4.40 \mathrm{~mm})(p<0.05)$.

Conclusion: When compared to scaling and root planing alone, the local drug delivery gel containing green tea catechin as an adjuvant was more effective in reducing the clinical parameters of periodontitis.
\end{abstract}

Keywords: Adjuvant therapy, Camellia sinensis, Local drug delivery, Periodontal pocket

\begin{abstract}
This is an Open Access article that uses a fund-ing model which does not charge readers or their institutions for access and distributed under the terms of the Creative Commons Attribution License (http://creativecommons.org/licenses/by/4.0) and the Budapest Open Access Initiative (http://www.budapestopenaccessinitiative.org/read), which permit unrestricted use, distribution, and reproduction in any medium, provided the original work is properly credited.

Tropical Journal of Pharmaceutical Research is indexed by Science Citation Index (SciSearch), Scopus, International Pharmaceutical Abstract, Chemical Abstracts, Embase, Index Copernicus, EBSCO, African Index Medicus, JournalSeek, Journal Citation Reports/Science Edition, Directory of Open Access Journals (DOAJ), African Journal Online, Bioline International, Open-J-Gate and Pharmacy Abstracts
\end{abstract}

\section{INTRODUCTION}

Chronic periodontitis is one of the most common oral health conditions. Among the various etiological agents, gram negative anaerobic micro-organisms such as Treponema denticola, Porphyromonas gingivalis, and Tannerella forsythia have significant role in the etiology of periodontal diseases [1].
The management of chronic periodontitis such as scaling and root planing and surgical therapies are aimed at eliminating the sub-gingival microflora responsible for local bacterial infection [2]. Complete bacterial elimination from periodontal pockets is often difficult due to the indigenous nature of the sub-gingival microflora, therefore the chances of repopulation after periodontal therapy is high [3]. Administration of systemic antibiotics specifically aimed at the 
periodontal pathogens, as an adjunct to mechanical therapy, has been recommended [4]. However, drug concentrations in the gingival crevicular fluid through systemic anti-microbial therapy do not attain the minimum inhibitory concentration (MIC) against the pathogenic microorganisms for a sustained period [5]. Several local drug delivery (LDD) systems containing anti-microbial agents have been introduced as adjunct to mechanical therapies for overcoming this limitation.

The various forms of LDD systems developed for periodontal therapy include gels, films, strips, and chips containing chlorhexidine, metronidazole, and/or doxycycline [6]. In recent years, several herbal extracts have been tested for their therapeutic effects, such as anti-oxidant, anti-inflammatory, anti-arthritic, anti-bacterial, anti-angiogenic, and anti-viral properties, owing to the adverse effects of synthetic drugs [7]. Green tea is one of the herbal products that has gained popularity for its health-promoting effects [8].

Green tea catechins have been found to inhibit the growth of periodontal pathogens such as $P$. gingivalis [9]. Thermoreversible gels are the recently developed LDD system that degrade slowly in the biologic environment to form safer by-products that provide long-term retention of the anti-microbial agent at the desired site [10]. Pluronic F-127 (PF-127), one of polyethylenepolyoxypropylene block copolymers, possesses the properties of low toxicity, reverse thermal gelation, and high drug loading rendering it suitable for use as an LDD system [11].

The objective of this study was to evaluate the efficacy of PF-127 gel containing green tea catechin extract in the treatment of chronic periodontitis.

\section{METHODS}

\section{Study subjects}

All patients visiting the outpatient clinic of the Department of Periodontics at the KSR Institute of Dental Sciences and Research, India were evaluated to determine their eligibility for the study. The selection of subjects for the study was based on inclusion and exclusion criteria. Patients aged between 20 and 40 years and with a probing pocket depth of 4-6 $\mathrm{mm}$ in the molars were included. Patients were excluded if they revealed one or more of the following conditions: smoking or tobacco-chewing habit, pregnancy, indication for definitive surgical therapy, and/or history of allergies. Patients with history of systemic diseases or of scaling and polishing of teeth within 6 months of commencement of the study were excluded. Patients on existing or past 3 months antibiotic therapy were also excluded. The purpose and outcomes of the research were explained to the patients, and a written informed consent was obtained from the subjects willing to participate in the research. Ethical approval was obtained from the Institutional Review Board, KSR Institute of Dental Sciences \& Research, India (no. 008/KSRIDSR/EC/2011). The research was conducted in compliance with the Helsinki Declaration of 1975 and its subsequent amendments [12].

\section{Pluronic F-127 gel preparation}

The green tea catechin extracts and the drug carrier polymer PF-127 were obtained from NESSO - Natural \& Essential Oils Pvt. Ltd. The extract consisted of $90 \%$ catechins (polyphenols), of which $45 \%$ consisted of epigallo catechin gallate (EGCg). The gel was prepared by adding $25 \mathrm{mg}$ green tea extract to 5 g PF-127 polymer using the cold process. A carefully weighed amount of PF-127, sufficient to yield a concentration of $20 \%$, was slowly added to cold water $\left(5^{\circ} \mathrm{C}\right)$ with constant stirring. The dispersion was refrigerated until a clear solution was obtained (after approximately 5 hours). The solution would convert to gel form at room temperature after removal from the refrigerator.

\section{Study design}

This research adopted a split-mouth randomized controlled study design (Figure 1). The two interventions included in the study were: scaling and root planing (SRP) alone and SRP followed by the placement of PF-127 gel, containing green tea catechin, in the periodontal pocket. The right and left quadrants were coded and only one molar satisfying the inclusion criteria of probing pocket depth of $4-6 \mathrm{~mm}$ was selected and recorded by the principal investigator. All subjects underwent phase I therapy including SRP at the first visit, and baseline scores for gingival index (GI), plaque index (PI), and probing pocket depth (PPD) were recorded (Figure 2 a). Only one investigator performed the clinical evaluations throughout the study. PF-127 gel containing green tea catechin was placed into the periodontal pocket of the molar randomly in either quadrant by the operating investigator. The molar receiving the PF-127 gel was coded for the test group, and the contralateral molar receiving SRP alone was coded for the control group (Figure 2 b). 
After placing the PF-127 gel containing green tea catechin into the periodontal pocket, a periodontal dressing (Coe-Pak TM, GC America Inc., IL, USA) was placed to protect the surgical site. The periodontal dressing was placed on the contralateral side only to ensure that the clinical examination during the follow-up visit was free of possible bias (Figure $2 \mathrm{c}$ ). All subjects were recalled after 14 days for re-application of the PF-127 gel. Only the operating investigator performed the re-application procedure in all the patients to obtain outcome investigator blinding. Follow-up evaluations were performed on the $28^{\text {th }}$ day, and scores for clinical indices were recorded.

\section{Statistical analysis}

The collected data were entered in a computer application (Microsoft Excel 2010) and subjected to statistical analysis using SPSS software version 16 (IBM Inc, Chicago, IL, USA). The data were analyzed using paired Student's and independent sample t-tests. The level of significance was set at $p<0.05$.

\section{RESULTS}

At baseline, the SRP and green tea catechin tooth sites showed no statistically significant differences in their mean GI, PI, and PPD scores $(p>0.05)$. At the $28^{\text {th }}$-day follow-up, the green tea catechin tooth sites showed significantly lower mean GI, PI, and PPD scores than the corresponding SRP tooth sites $(p<0.05$, Table 1). Table 2 shows the mean GI, PI, and PPD scores of the SRP and green tea catechin tooth sites at baseline and at the $28^{\text {th }}$-day follow up. Both SRP and green tea catechin group showed statistically significant reduction in their mean Gl, $\mathrm{PI}$, and PPD scores from baseline to the $28^{\text {th }}$-day followup $(p<0.05$, Table 2). The mean differences in GI, PI, and PPD scores were greater among the green tea catechin tooth sites than that among the SRP sites (Table 2).

Table 1: Gingival index, plaque index, and probing pocket depth scores at baseline and at the $28^{\text {th }}$-day follow up $(N=20)$

\begin{tabular}{|c|c|c|c|c|c|c|}
\hline Parameter & & Group & Mean $\pm S D$ & $\mathbf{t}$ & df & $P$-value \\
\hline \multirow{4}{*}{$\begin{array}{l}\text { Gingival } \\
\text { index }\end{array}$} & & SRP & $2.30 \pm 0.571$ & 0.282 & 38 & 0.780 \\
\hline & Baseline & Green tea catechin & $2.25 \pm 0.550$ & & & \\
\hline & & SRP & $1.25 \pm 0.550$ & 3.829 & 38 & $0.000^{*}$ \\
\hline & After 28 days & Green tea catechin & $0.55 \pm 0.605$ & & & \\
\hline \multirow{4}{*}{ Plaque index } & & SRP & $2.05 \pm 0.224$ & 0.000 & 38 & 1.000 \\
\hline & Baseline & Green tea catechin & $2.05 \pm 0.224$ & & & \\
\hline & & SRP & $1.15 \pm 0.366$ & 6.378 & 38 & $0.000^{\circ}$ \\
\hline & After 28 days & Green tea catechin & $0.30 \pm 0.470$ & & & \\
\hline \multirow{4}{*}{$\begin{array}{l}\text { Probing } \\
\text { pocket depth }\end{array}$} & & SRP & $5.25 \pm 0.55$ & 0.902 & 38 & 0.373 \\
\hline & Baseline & Green tea catechin & $5.05 \pm 0.83$ & & & \\
\hline & & SRP & $4.40 \pm 0.82$ & 4.653 & 38 & $0.000^{*}$ \\
\hline & After 28 days & green tea catechin & $3.35 \pm 0.59$ & & & \\
\hline
\end{tabular}

Statistically significant difference; SRP: scaling and root planing; SD: standard deviation

Table 2: Gingival index, plaque index, and probing pocket depth scores within groups at baseline and at the $28^{\text {th }}$ day follow up $(n=28)$.

\begin{tabular}{|c|c|c|c|c|c|c|c|}
\hline Parameter & & Assessment & Mean $\pm S D$ & $\begin{array}{c}\text { Mean } \\
\text { difference }\end{array}$ & $t$ & df & $P$-value \\
\hline \multirow[t]{2}{*}{ Gingival index } & SRP & $\begin{array}{l}\text { Baseline } \\
\text { after } 28 \text { days }\end{array}$ & $\begin{array}{l}2.30 \pm 0.571 \\
1.25 \pm 0.550\end{array}$ & 1.05 & 9.200 & 19 & 0.000 \\
\hline & $\begin{array}{l}\text { Green tea } \\
\text { catechin }\end{array}$ & $\begin{array}{l}\text { Baseline } \\
\text { after } 28 \text { days }\end{array}$ & $\begin{array}{l}2.25 \pm 0.550 \\
0.55 \pm 0.605\end{array}$ & 1.70 & 10.376 & 19 & $0.000^{\circ}$ \\
\hline \multirow[t]{2}{*}{ Plaque index } & SRP & $\begin{array}{l}\text { Baseline } \\
\text { after } 28 \text { days }\end{array}$ & $\begin{array}{l}2.05 \pm 0.224 \\
1.15 \pm 0.366\end{array}$ & 0.9 & 13.077 & 19 & $0.000^{*}$ \\
\hline & $\begin{array}{l}\text { Green tea } \\
\text { catechin }\end{array}$ & $\begin{array}{l}\text { Baseline } \\
\text { after } 28 \text { days }\end{array}$ & $\begin{array}{l}2.05 \pm 0.224 \\
0.30 \pm 0.470\end{array}$ & 1.75 & 14.226 & 19 & $0.000^{*}$ \\
\hline \multirow{2}{*}{$\begin{array}{l}\text { Probing pocket } \\
\text { depth }\end{array}$} & SRP & $\begin{array}{l}\text { Baseline } \\
\text { After } 28 \text { Days }\end{array}$ & $\begin{array}{l}5.25 \pm 0.550 \\
4.40 \pm 0.821\end{array}$ & 0.85 & 5.667 & 19 & $0.000^{\circ}$ \\
\hline & $\begin{array}{l}\text { Green tea } \\
\text { catechin }\end{array}$ & $\begin{array}{l}\text { Baseline } \\
\text { after } 28 \text { days }\end{array}$ & $\begin{array}{l}5.05 \pm 0.826 \\
3.35 \pm 0.587\end{array}$ & 1.7 & 13.309 & 19 & $0.000^{*}$ \\
\hline
\end{tabular}

Statistically significant; SRP: scaling and root planing; SD: standard deviation 


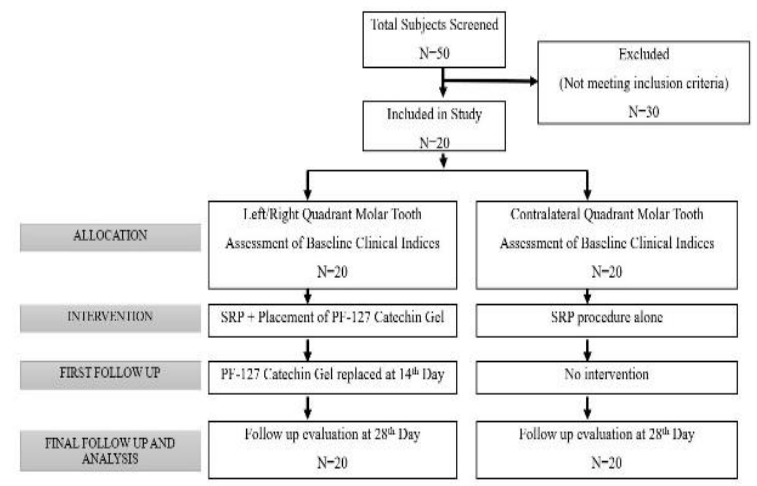

Figure 1: Flow chart of study design

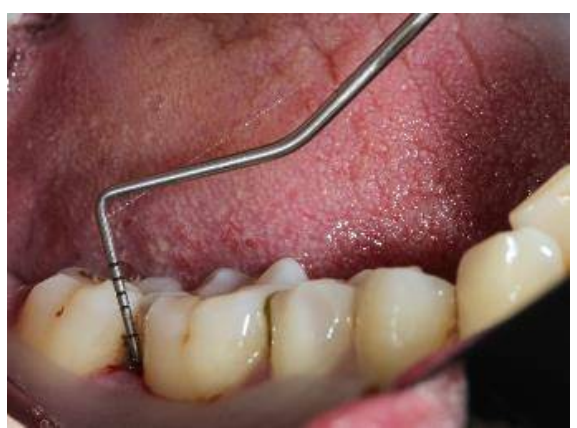

(a)

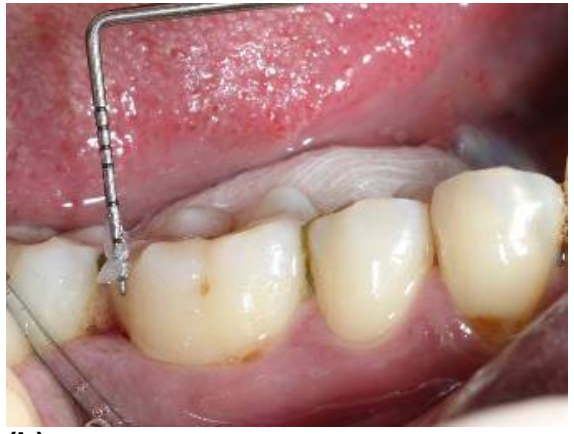

(b)

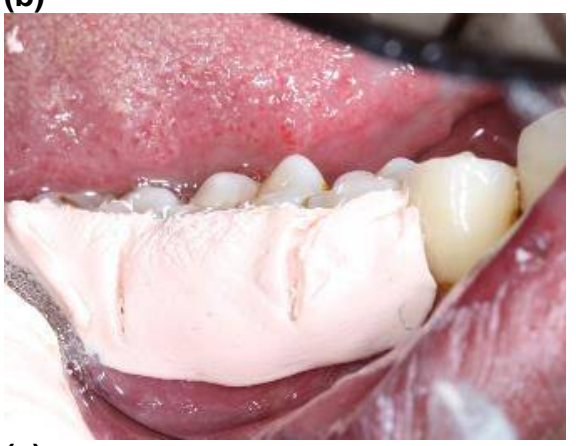

(c)

Figure 2: Location of thermoreversible gel containing catechins. (a) Pre-operative probing pocket depth; (b) Insertion of PF-127 gel with Green tea extract; (c) Periodontal pack in place

\section{DISCUSSION}

Consumption of the beverage tea originated in China around 2700 BC [13]. Based on the manufacturing process, tea can be broadly classified into three main types: fermented black and red tea, semi-fermented oolong tea, and non-fermented green tea. The most widely produced and consumed variety is the black tea, followed by the green and oolong tea. Green tea is manufactured from the shrub Camelia sinensis, which is known for its health-promoting effects. The major constituents of green tea are polyphenols, which comprise flavanols, flavonoids, and phenolic acids. Flavanols are also known as catechins. Catechin, gallaocatechin, epicatechin, epigallocatechin, epicatechin gallate (ECG), and epigallocatechin gallate $(E G C g)$ are the primary catechins in green tea. EGCg is among the most studied polyphenol component of green tea. Catechins possess anti-oxidant, anti-carcinogenic, and antiinflammatory properties $[14,15]$. Recently, the anti-microbial property of catechins has become a subject of extensive research [16].

Development of chronic periodontitis in adults is influenced by a combination of periodontal pathogens, host, and environmental factors. Tissue damage is aggravated by excessive release of proteolytic enzymes and reactive oxygen species [17]. There is a steady release in reactive oxygen species such as superoxide $\mathrm{CO}_{2}^{-}$ ), hydroxyl $(\mathrm{OH})$, and nitric oxide (NO) in the healthy periodontium. The tissue-damaging effects of free radicals could be the result of mutations in DNA, which eventually could lead to cell death. Free radicals trigger interleukin (IL)-1induced osteoclastic bone resorption [14]. Antioxidants in green tea can neutralize the harmful effects of free radicals and promote the health of the periodontium.

Mechanical periodontal therapy such as SRP remains the conventional first line therapy for the elimination of local etiological factors. However, complete elimination of bacterial plaque is difficult by the use of mechanical periodontal therapy alone. Adjuvant systemic antibiotic therapy to mechanical periodontal therapy requires high antibiotic dosages for a prolonged period to attain the necessary MIC in the periodontal pockets.

Advances in the management of periodontal diseases to overcome the limitations of systemic route of drug delivery have led to the development of several LDD systems. Use of high-viscosity hydrophilic gels is one of the approaches for controlled drug delivery at desired site. Thermoreversible gels are newer pharmaceutical formulations that have the capacity to make, break, and/or modify the bonds responsible for holding the molecular network. 
They are liquid when refrigerated $\left(4-5^{\circ} \mathrm{C}\right)$, but gel upon warming to room temperature [18]. PF127 has been used as a carrier for various routes of drug administration including ocular application [19]. This is the first study to use green tea catechin extract coupled with PF-127 gel in the management of chronic periodontitis.

In this study, both test and control group tooth sites, i.e., SRP with green tea catechin and SRP alone, respectively, showed significant reduction in clinical parameters of periodontitis. However, the reduction in mean scores was greater with green tea catechin adjuvant group for all the clinical parameters. Mechanical therapies are simply based on the elimination of local etiological factors. Hence, improvement in the clinical indices is expected. The plaque-inhibitory effects of green tea catechins could be the result of the anti-bacterial properties of catechin fractions. ECG is found to be effective in mitigating bacterial virulence by neutralizing toxic metabolites. Penetration of catechin gallates by displacing lipoteichoic acid of the bacterial lipid bilayer has shown to modulate the sensitivity of methicillin-resistant staphylococcus aureus to $\beta$ lactam antibiotics[13].

Green tea extracts in mouthwashes are effective in reducing plaque scores [20]. The reduction in Gl scores observed in this study is in agreement with the results of similar studies that used strips impregnated with green tea extracts [21,22]. EGCg inhibits interleukin (IL)-1, -6 , and -8 and enzymes such as lipooxygenase, cyclooxygenase, and matrix metalloproteinase-1, which are responsible for the production of several other inflammatory mediators [23]. The anti-collagenase property of catechins prevents bone resorption and thereby aids in the reduction in pocket depths [24]. Green tea catechins are known inhibitors of cysteine proteinases (Arggingipain and Lys-gingipain) of $P$. gingivalis and protein tyrosine phosphatase of Prevotella intermedia, which are considered potent virulence factors in the development of periodontitis, and thus reduce the potential periodontal breakdown $[25,26]$.

This study attempted to test the efficacy of green tea extracts in the treatment of chronic periodontitis using PF-127 gel as an LDD vehicle. The limitations of this study include a small sample size and the incorporation of individual tooth sites in analyzing the interventions. Further studies with larger sample sizes involving full-mouth interventions need to be conducted to validate the use of green tea extracts for the treatment of chronic periodontitis.

\section{CONCLUSION}

When compared to scaling and root planing alone, the local drug delivery gel containing green tea catechin as an adjuvant is more effective in reducing the clinical parameters of periodontitis. Thus, green tea catechins is a potentially effective local drug delivery agent in adjunct to conventional periodontal therapy in moderate to deep periodontal pockets.

\section{DECLARATIONS}

\section{Acknowledgement}

The authors are grateful to Dr Pramod, of JSS College of Pharmacy for helping with the preparation of PF-127 gel with green tea catechin extracts.

\section{Conflict of interest}

No conflict of interest is associated with this work.

\section{Contribution of authors}

We declare that this work was done by the authors named in this article and all liabilities pertaining to claims relating to the content of this article will be borne by the authors.

\section{Open Access}

This is an Open Access article that uses a funding model which does not charge readers or their institutions for access and distributed under the terms of the Creative Commons Attribution License (http://creativecommons.org/licenses/by/ 4.0) and the Budapest Open Access Initiative (http://www.budapestopenaccessinitiative.org/rea d), which permit unrestricted use, distribution, and reproduction in any medium, provided the original work is properly credited.

\section{REFERENCES}

1. Zhu Y, Dashper SG, Chen $Y Y$, Crawford S, Slakeski $N$, Reynolds EC. Porphyromonas gingivalis and Treponema denticola synergistic polymicrobial biofilm development. PloS one 2013; 8(8): e71727.

2. Greenstein G. Nonsurgical Periodontal Therapy: A Literature Review. J Am Dent Assoc 2000; 131(11): 1580-1592.

3. Shiloah J, Patters MR. Repopulation of Periodontal Pockets by Microbial Pathogens in the Absence of Supportive Therapy. J Periodontol 1996; 67(2): 130-139. 
4. Goodson JM, Hogan PE, Dunham SL. Clinical responses following periodontal treatment by local drug delivery. $J$ Periodontol 1985; 56(11): 81-87.

5. Szulc M, Zakrzewska A, Zborowski J. Local drug delivery in periodontitis treatment: $A$ review of contemporary literature. Dent Med Probl 2018; 53(3): 333-342.

6. Greenstein G, Polson A. The role of local drug delivery in the management of periodontal diseases: a comprehensive review. J Periodontol 1998; 69(5): 507520.

7. Ramesh A, Varghese SS, Doraiswamy JN, Malaiappan S. Herbs as an antioxidant arsenal for periodontal diseases. J Intercult Ethnopharmacol 2016; 5(1): 92-96.

8. Sinija VR, Mishra HN. Green tea: Health benefits. Journal of Nutritional and Environmental Medicine 2008; 17(4): 232-242.

9. Yuvaraja M, Reddy NR, Kumar PM, Ravi KS, Alqahtani $N$. Thermoreversible gel for intrapocket delivery of green tea catechin as a local drug delivery system: An original research. J Adv Pharm Technol Res 2016; 7(4): 139143.

10. Mansour M, Mansour S, Mortada ND, Abd Elhady SS. Ocular poloxamer-based ciprofloxacin hydrochloride in situ forming gels. Drug Dev Ind Pharm 2008; 34(7): 744752.

11. Gilbert JC, Hadgraft J, Bye A, Brookes LG. Drug release from Pluronic F-127 gels. Int J Pharm 1986; 32(2): 223 8.

12. World Medical Association (WMA). Declaration of Helsinki: Ethical principles for research involving human subjects. JAMA 2013; 310(20): 2191-2194.

13. Taylor PW, Hamilton-Miller JM, Stapleton PD. Antimicrobial properties of green tea catechins. Food Sci Technol Bull 2005; 2: 71-81.

14. Chapple IL, Matthews JB. The role of reactive oxygen and antioxidant species in periodontal tissue destruction. Periodontol 2000 2007; 43: 160-232.

15. Nugala $B$, Namasi $A$, Emmadi $P$, Krishna $P$. Role of green tea as an antioxidant in periodontal disease: The Asian Paradox. J Indian Soc Periodontol 2012; 16(3): 313-316.

16. Reygaert WC. The antimicrobial possibilities of green tea. Front. Microbiol 2014; 5: 434
17. Figueredo CM, Gustafsson A, Asman B, Bergstrom $K$. Increased release of elastase from in vitro activated peripheral neutrophils in patients with adult periodontitis. J Clin Periodontol 1999; 26(4): 206-211.

18. Jørgensen EB, Hvidt S, Brown W, Schillén K. Effects of Salts on the Micellization and Gelation of a Triblock Copolymer Studied by Rheology and Light Scattering. Macromolecules 1997; 30(8): 2355-2364.

19. El-Kamel AH. In vitro and in vivo evaluation of Pluronic F127-based ocular delivery system for timolol maleate. Int J Pharm 2002; 241(1): 47-55.

20. Kaur H, Jain S, Kaur A. Comparative evaluation of the antiplaque effectiveness of green tea catechin mouthwash with chlorhexidine gluconate. J Indian Soc Periodontol 2014; 18(2): 178-182.

21. Gadagi JS, Chava VK, Reddy VR. Green tea extract as a local drug therapy on periodontitis patients with diabetes mellitus: A randomized case-control study. J Indian Soc Periodontol 2013; 17(2): 198-203.

22. Hattarki SA, Pushpa SP, Bhat K. Evaluation of the efficacy of green tea catechins as an adjunct to scaling and root planing in the management of chronic periodontitis using PCR analysis: $A$ clinical and microbiological study. J Indian Soc Periodontol 2013; 17(2): 204-209.

23. Ahmed S, Wang N, Lalonde M, Goldberg VM, Haqqi TM. Green tea polyphenol epigallocatechin-3-gallate (EGCG) differentially inhibits interleukin-1 beta-induced expression of matrix metalloproteinase-1 and -13 in human chondrocytes. J Pharmacol Exp Ther 2004; 308(2): 767-773.

24. Madhan B, Krishnamoorthy G, Rao JR, Nair BU. Role of green tea polyphenols in the inhibition of collagenolytic activity by collagenase. Int J Biol Macromol 2007; 41(1): 16-22.

25. Okamoto M, Leung KP, Ansai T, Sugimoto A, Maeda $N$. Inhibitory effects of green tea catechins on protein tyrosine phosphatase in Prevotella intermedia. Oral Microbiol Immunol 2003; 18(3): 192-195.

26. Okamoto $M$, Sugimoto $A$, Leung $K P$, Nakayama $K$, Kamaguchi A, Maeda N. Inhibitory effect of green tea catechins on cysteine proteinases in Porphyromonas gingivalis. Oral Microbiol Immunol 2004; 19(2): 118-120. 